\title{
Melampaui Pengenalan Untuk Mengalami Yesus Tinjaun Teori Kognitif Piaget berdasarkan Matius 16:13-20
}

\author{
Alexander Lukas, Angelia Budiman, Resty Sari Somakila' \\ Yesika Falensia \\ Email: alexzanderlukas449@gmial.com¹, angeliamerry24@gmail.com² ${ }^{2}$,restysomakila@gmail.com³ \\ yesicharis@gmail.com ${ }^{4}$ \\ Sekolah Tinggi Filsafat Theologia Jaffray Makassar
}

\begin{abstract}
Abstrak
Banyak orang Kristen yang mengalami Kristen KTP. Mereka telah menajdi Kristen sejak mereka dilahirkan dan memiliki status agaama Kristen di Kartu Tanda Pengenal (KTP). Namun ketika mereka diberi pertanyaan mengenai siapakah Yesus bagi mereka, banyak diantara mereka yang bingung untuk menjawab pertanyaan tersebut. Sebagian besar akan menjawab secara umum bahwa Yesus adalah Tuhan. Hal ini disebabkan karena banyak dianatara mereka yang hanya mengenal Yeusu secara kognitif mereka, tetapi tidak mengalami Yesus secara pribadi. Tujuan penelitian ini adalah mendorong seriap orang Kristen untuk memahami Yesus tidak hanya melalui pengenalan tetapi juga melalui pengalaman bersama Yesus berdasarkan teori Kognitif Piget yang dihubungkan dengan Matius 16:13-20. Penelitian ini adalah penelitian kualitatif dengan menggunkan metode 5P yang mengamati 20 mahasiswa mata kuliah Psikologi Umum di STFT Jaffray Makassar. Hasil penelitian menemukan bahwa banysk mahasiswa yang menyadari bahwa mereka hanya sebatas mengenal Yesus dan tidak mengalami Yesus secara pribadi. Dan cara untuk mengnal Yesus adalah membangun hubungan yang intim dengan Yesus melalu doa teduh secara rutin. Melalui doa teduh setiap pribadi merenungkan cara Yesus bekerja dalam hidupnya dan menciptakan pengalaman pribadi dengan Yesus.
\end{abstract}

Kata kunci: orang Kristen, mengenal, kognitif, mengalami, Yesus

\section{Pendahuluan}

Kartu Tanda Penduduk (KTP) adalah identitas kita sebagai penduduk negara Indonesia. Demikian juga agama kita adalah identitas kita secara spiritual kita. Namun banyak orang Kristen yang tidak sadar akan identitas mereka. Hal ini dapat disebabkan karena banyak orang Kristen yang hanya sebatas mengenal Allah secara kognitif karena pengaruh atau keadaan lingkungan. Namun mereka belum mengenal Yesus secara pribadi.

Di era sekarang ini, istilah "Kristen KTP" merupakan fenomena yang sedang tren di kalnagan orang Kristen. Istilah Kristen KTP adalah fenomena dimana seorang Kristen secara sah dalam Kartu Tanda Penduduk beragama Kristen namun tidak dapat mecerminkan ataupun mempraktekkan nilai-nilai kekristenan dalam kehidupannya sehari-hari. Bahkan banyak dianatara mereka yang sejak lahir telah beragama Kristen karena kedua orang tuanya adalah Kristen. 
Orang-orang yang mengalami Kristen KTP secara tidak langsung mengikuti aliran dualisme agama dan kebuadayaan. Sikap ini disebut sebagai sikap mendua karena seakan memisahkan iman dan kebudayaan. ${ }^{1}$ Jika dianalogikan aliran ini seperti seseorang berdiri dengam kaki kanan yang berdiri di agama Kristen sedangkan kaki kirinya berada di dunia Hal ini terlihat dari orang Kristen KTP yang kelihatannya taat mengikuti ajaran agama di gereja. Namun setelah keluar dari lingkungan gereja maka mereka kembali lagi dengan kehidupan yang tidak mencerminkan Kekristenan.

Secara tersirat fenomena ini juga terjadi dalam Perjanjian Baru yaitu terdapat dalam Matius 16:13-20. Yesus memiliki 12 murid yang mengikut Dia dan memberitakan injil tentang Dia. Mendengar injil tersebut, banyak orang yang berbondong-bondong mengikuti Dia karena perbuatan-perbuatan ajaib yang dilakukanNya. Namun Herodes penasaran dengan siapa yang sedang diberitakan oleh 12 muridmurid. Hingga akhirnya Yesus bertanya langsung dengan murid-murin-Nya tentang pandangan orang banyak tentang diri-Nya.

Dan ternyata orang-orang yang berbobndong-bondong tersebut tidak mengenal bahwa Dia adalah Yesus. Bahkan mereka menganggap bahwa Yeusu adalah Yohanes Pemabptis, Elia dan nabi-nabi terdahulu yang bangkit. Namun ketika Yesus bertanya kepada salah satu murid-Nya yaitu Petrus, maka Petrus menjawab bahwa Yesus adalah Mesias dari Allah. Hal ini menunjukkan bahwa Petrus mengenal dan mengalami Yesus. Petrus dan murid-murid Yesus telah mengalami Yesus karena mereka memiliki hubungan yang intim dengan Yesus.

Pengenalan adalah aktivitas yang melibatkan otak. Aktivitas otak ini melibatkan proses berpikir. Dalam psikologi ranah ini disebut sebagai kognitif. Dalam psikologi kognitif berhubungan dengan kegiatan mengenal secara psikis yang mencakup pengenalan melalui pengertian, pemahaman, pengeloalaan informasi, pemecahan masalah, berpikir dan sebagainya. ${ }^{2}$ Dalam teori belajar tingkah laku dan pola pikir seseorang dianggap sebagai wujud dari presepsinya dan pemahamannya akan objek yang dilihat. Sehingga teori kognitif merupakan teori belajar yang mementingkan proses belajar karena dalam proses inilah siswa dapat memahami, mengerti dan bahkan berfikir yang melibatkan aktivitas otaknya. ${ }^{3}$ Teo ri kognitif disusun oleh Dewwy, dilanjutkan oleh Jean Piget, Kohlberg, Damon, Mosher, Perry, dan tokoh lainnya. ${ }^{4}$ Piget adalah seorang tokoh psikologi yang berkata bahwa kemampuan berfikir seseorang bergantung dari tahap perkembangan dan umur pribadi. ${ }^{5}$

Berdasarkan isu dan fenomena tersbut, maka tim penulis maka menguraikan pentingnya pengenalan yang harus disertakan dengan pengalaman bersama Yesus yang dihubungkna dengan Matius 16:13-20. Selanjutnya tim penulis akan medeskripsikan hasil penelitian kualitatif yang dilakukan. Dan pada bagian akhir akan dibahas mengenai kesimpulan dari penelitian.

\section{Kanjian Teori}

Manusia diciptakan oleh Tuhan sebagai makhluk yang istimewa karena memiliki akal dan pikiran. Kedua hal inilah yang membedakan manusia dengan makhluk ciptaan Tuhan yang lainnya. Melalui akal dan pikiran yang dimiliki,

\footnotetext{
${ }^{1}$ Kelompok Kerja Pendidikan Agama Kristen PGI, Suluh Siswa 2: Berbuah dalam Kristus (Buku Pendidkan Agama Kristen kelas 11 SMA) (Jakarta: PT. BPK Gunung Mulia, 2209).

${ }^{2}$ Mimi, Perkembangan Peserta Didik (Padang: IAIN IB Press, 2011).

${ }^{3}$ Haryanto Suyono, Teori Belajar dan Pembelajaran (Bnadung: Remaja Rosdakarya, 2010).

${ }^{4}$ Sutarto, "Teorii Koognitif dan Implikasinya dalam Pembelajaran," Jurnal Konseling Islam, 1 (2017), 2 .

${ }^{5}$ Ibid.
} 
seharusnya manusia dapat bertingkah laku sesuai dengan kodratnya sebagai "individu manusia".Yuliani Nurani Sujiono, "Hakikat Pengembangan Kognitif," t.t., 1-35.

Oleh sebab itu kita sebagai manusia kita memiliki akal dan pikiran, dan ini mempengaruhi cara bertingkah laku kita sebagai mahkluk yang istimewa karena cara kita bertindak dan bertingkah laku itu dipengaruhi oleh pikiran dan akal kita. Sebagai manusia yang miliki akal dan pikiran dan melakukan tindakan atau bertingkah laku, bahwa ini semua berkaitan dengan teori kognitif, dimana teori kognitif ini berhubungan dengan pikiran atau cara bepikir kita baik pengatahuaan dan dari semuanya Itu mempengaruhi tindakan kita sebagai manusia individu.

Proses teori kognitif adalah proses kognitif melibatkan berbagai indra kita, yaitu penglihatan, penciuman, perasaan, pengecapan, dan pendengaran. Disamping itu kesadaran dan perasaan. ${ }^{6}$

Pengalaman adalah salah satu kunci untuk kita memperoleh pengatahuaan. Dalam proses untuk kita memperoleh pengetahuan bagian-bagian dalam indra kita itu sangat berperan penting untuk kita memperoleh pengetahuan karena indra kita ini terdiri dari penglihatan bahwa dimana kita bisa melihat lingkungan kita, penciuman, perasaan, pengecapan, dan pendengaran. Dari semuanya itu kita akan memperoleh pengetahuan apabila semuanya itu bekerja dengan baik.

Dalam teori kognitif memiliki pendekatan klasik, yaitu

1. Pendekatan behaviouris, mempelajari mekanika dasar pembelajaran. Pendekatan tersebut memberikan perhatian terhadap bagaimana perilaku berubah sebagai respon terhadap sebuah pengalaman;

2. Pendekatan psikometris, mencoba mengukur perbedaan kuantitatif dalam kemampuan kognitif dengan menggunakan tes yang mengindikasikan kemampuan ini;

3. Pendekatan piagetian, memperhatikan perubahan atau langkah-langkah, dalam kualitas fungsi kognitif. Pendekatan tersebut memberikan perhatian tentang bagaimana pikiran menstruktur aktivitasnya dan beradaptasi dengan lingkungannya.Sujiono.

Ketiga pendekatan ini sangat membantu kita dalam memahami perkembagan atau proses dari kognitif. Dan dari pendekatan ini kita bisa lihat bahwa dalam kita mengukur dan melihat suatu pekebmbangan kognitif, kita perlu melakukan tiga pendekatan ini yaitu pedekatan behavioris yang dalam melakukan sesuatu dilihat dari respon, pendekatan psikometoris yaitu mengukur dan menggunakan tes untuk memperoleh hasil, dan terakhir pendekatan piagetin bertujuan memberi perhatian kepada pikiran menstruktur.

\section{Teori kognitif menurut para ahli}

Menurut Fiske and Taylor kognitif memusatkan pada bagaiamana kita memproses informasi yang datangnya dari lingkungan ke dalam struktur mental kita Teori-teori kognitif percaya bahwa kita tidak bisa memahami perilaku sosial tanpa memperoleh informasi tentang proses mental yang bisa dipercaya, karena informasi tentang hal yang obyektif, lingkungan eksternal belum mencukupi.Hasan Mustafa, "Perilaku Manusia Dalam Perspektif Psikologi Sosial” 7, no. 2 (2012): 143-56.

Mengolah dan memproses informasi dari lingkungan. Oleh sebab itu dalam mengolah informasi kita memperoleh informasi karena kita tidak bisa mengerti prilaku sosial kalau kita tidak memiliki informasi yang jelas tentang proses yang masuk kedalam struktur mental kita.

${ }^{6}$ Kushartanti, Untung Yuwono, dan Multamia, ed., Pesona Bahasa: Langkah Awal Memahami Linguistik (Jakarta: Gramedia Pustaka Umum, 2014). 
Menurut Jerome Brunner, pembelajaran hendaknya dapat menciptakan situasi agar dapat belajar dari diri sendiri melalui pengalaman dan eksperimen untuk menemukan pengetahuan dan kemampuan baru yang khas baginya.Jum Anidar, "Teori Belajar Menurut Aliran Kognitif Serta Implikasinya Dalam Pembelajaran,” 2014.

Pengalaman adalah membuat kita mengasah pemikiran dan akal kita untuk memperoleh pengatahuan yang kita peroleh dari apa yang kita belajar.

Menurut Piaget, anak dilahirkan dengan beberapa skemata sensorimotor, yang memberi kerangka bagi interaksi awal anak dengan lingkungannya. Pengalaman awal si anak akan ditentukan oleh skemata sensorimotor ini. Dengan kata lain, hanya kejadian yang dapat diasimilasikan ke skemata itulah yang dapat di respons oleh si anak, dan karenanya kejadian itu akan menentukan batasan pengalaman anak.

Ketika kita dilahirkan, pengalaman kita akan di tentukan oleh sensorimotor karena ketika kita lahir kita memiliki beberapa sensorimotor dan itu membuat kita mengalami dan mempunya pengalaman dari situlah kita belajar dan memperoleh pengatahuan.

\section{Alasan mengambil nas Matius 16:13-20}

Dalam nas ini menceritakan tentang Yesus dan murid-muridnya pada saat mereka tiba di daerah Kaisarea. Dan di situ Yesus bercakap-cakap dengan muridmuridNya. Yesus bertanya kepada murid-muridNya "siapakah anak manusia itu?" dan sangat menarik disini bahwa Yesus mengeluarkan pertanyaan seperti itu kepada muridmuridNya. Apa maksud dari Yesus memberi pertanyaan itu kepada murid-muridNya. Apakah murid-muridnya tidak mengatahui siapa anak manusia itu. Karena dari jawaban mereka ada yang mengatakan Yohanes pembabptis, ada yang mengatakan Elia dan ada juga mengatakan Elia. Jawaban inilah yang muncul ketika Yesus bertanya kepada mereka.

Dalam kehidupan orang percaya saat ini banyak dari orang percaya mereka mempertanyakan Yesus dalam kehidupan mereka walaupun mereka sudah percaya kepada Dia. Namun seringkali kita masih mempertanyakan tentang Yesus. Apakah Dia benar-benar ada dalam kehidupan kita atau tidak. Inilah yang terus berkembang dalam kehidupan orang percaya.

Oleh sebab itu orang kristen atau orang percaya kepada Yesus. Jangan jadikan identitas kita yaitu sebagai orang kristen dan orang percaya hanya untuk dilihat dan dikenal orang saja. Namun jadikan identitas itu sebagai bukti bahwa Allah mengenal kita.

Dari nas yang diambil ini membuktikan bahwa murid-murid Yesus masih bingung dan tidak tau siapakah anak manusia itu. Oleh sebab itu dari cerita ini kita bisa belajar bahwa ada yang masih mempertanyakan tentang Yesus. Dan juga dari nas ini bahwa petrus mengenal Dia. Sebagai orang percaya kita harus mengenal Dia baik dalam pikiran kita. Kita harus mengatahui tentang Yesus, namun kita harus mengenal Dia dan mengalami Yesus dalam kehidupan kita. Itu adalah identitas kita sebagai orang percaya yang mengatahui atau mengenal Yesus dan mengalami Yesus dalam kehidupan kita.

Itulah alasan bahwa banyak orang yang menjadi pengikut Yesus tapi mereka tidak mengatahui tentang Dia. Oleh sebab itu kita perlu mengenal dan mengalami Yesus dalam kehidupan kita. 


\section{Hubungan teori kognitif dengan nas Matius 16:13-20}

Dalam menghubungkan teori dengan nas kami mengambil teori kognitif yang di kembangkan oleh Jean Piaget. Dimana teori kognitif ini mengarah kepada pemahaman dan cara bepikir sesorang

Dan ini adalah tahapan-tahapan kognitif Jean Piaget Pertama, pola/skema (schemas). Piaget menyatakan bahwa ketika anak berusah membangun pemahaman mengenai dunia,otak berkembang membentuk skema, Kedua, asimilasi Asimilasi pada dasarnya tidak mengubah skema, tetapi mempengaruhi atau memungkinkan pertumbuhan skema. Asimilasi adalah proses kognitif individu dalam usahanya untuk mengadaptasikan diri dengan lingkungannya, Ketiga, akomodasi. Akomodasi adalah suatu proses struktur kognitif yang belangsung sesuai dengan pengalaman baruKeempat, keseimbangan adalah keseimbangan antara proses-proses asimilasi dan akomodasi.

Jadi Jean Piaget dalam berkembangnya kognitif memiliki empat tahapan yaitu yang pertama pola skema ialah membagun pemahaman mengenai otak sehingga terbentuknya skema, kedua asimilasi adalah untuk mempengaruhi skema untuk bertumbuh, ketiga akomodasi adalah suatu perubahan yang dimana sekema menyesuaikan dengan informasi atau pengalaman baru yang diterima, dan keempat keseimbangan adalah suatu proses bahwa seseorang individu beralih dari satu tahap ke tahap berikutnya.

Menjadi hubungan teori kognitif dengan nas ini bahwa di mana dalam nas ini banyak orang yang mempertanyakan tentang anak manusia itu siapa atau mempertanyakan Yesus dalam kehidupan mereka. Dalam kita mengenal Yesus kita perlu memiliki pemahaman yang benar yang akan mengarah kepada skema kita oleh sebab itu skema kita harus berkembag terus dengan memberikan asimulasi karna asimulasi sangat mempengaruhui pertumbuhan skema kita dan juga akomodasi berperang untuk meluruskan skema kita, atau mengapdet untuk menjadi lebih baik. Dan terakhir bahwa perlu ada kesinambungan bahwa ketika kita mengenal Yesus dan mengalami Yesus dalam kehidupan kita. Kita perlu terus mengenal dan mengalami Dia. Inilah di mana kita mengalami proses bahwa kita beralih dari satu tahap ke tahap berikutnya.

\section{Metode}

Penelitian kualitatif ${ }^{7}$ dengan metode $5 \mathrm{P}$ berbasis $3 \mathrm{C}$ menjadi metode yang dipilih oleh tim peneliti. 5P adalah kenpanjangan dari Penghubung, Pelajaran, Penerapan, Perubahan, dan Penutup. Adapun 3C adalah Creativite, Communication, and Collaboration. Model pembelajaran kooperatif berbasis media sosial menjadi model pembelajaran di dalam kelas. ${ }^{8}$ Adapun dalam menyusun tahapan pengumpulan data, tim peneliti menggunakan tindakan kelas dan aktivitas kelas.

Dalam kegiatan aktivitas kelas, mahasiswa diharapkan dapat :

1) Memahami arti mengenal dan mengalami Yesus

2) Menyadari dan mengintropeksi pengenalam terhadap Yesus

3) Membangun hubungan pribadi dengan Yesus

Adapun tahapan pengumpulan data dalam penelitian ini yakni sebagai berikut.

\footnotetext{
${ }^{7}$ Hengki Wijaya dan Helaluddin Helaluddin, Analisis Data Kualitatif Sebuah Tinjauan Teori \& Praktik (Makassar: Sekolah Tinggi Theologia Jaffray Makassar, 2019).

${ }^{8}$ Hengki Wijaya dan Arismunandar Arismunandar, "Pengembangan Model Pembelajaran Kooperatif Tipe STAD Berbasis Media Sosial,” Jurnal Jaffray 16, no. 2 (6 Oktober 2018): 175-96, https://doi.org/10.25278/jj71.v16i2.302.
} 
1) Penghubung

Semua murid duduk di bangku. Sukarelawan yang mengambil peran melakukan drama bersiap-siap. Narator akan membaca ayat firman Tuhan dari injil Matius 16: 13-20.dan setiap pemeran mendengar cerita akan memikirkan dan melalakukan bagian firman Tuhan tersebut.

Ceritalah: Apa yang saudara pahami tentang kejadian di peristiwa dalam cerita yang didramkan itu?

2) Pelajaran

Dalam setiap kelompok ceritakan ulang cerita yang telah di dramakan Kemudian, diskusikanlah dengan kelompok mengapa Yesus bertanya tentang diri-Nya kepada murid-murid-Nya?

Tuliskan kata kunci dalam cerita tersebut pada sticky note dan tempelkan pada kertas yang disediakan di depan.

3) Penerapan

Apa saja yang saudara pikiran dan lakukan apabila anda mengalami situasi seperti itu?

Tuliskan kata kunci dalam cerita tersebut pada sticky note dan tempelkan pada kertas yang disediakan di depan.

4) Perubahan

Refleksi: Kebanyakan orang Kristen dalam kehidupan rohaninya, hanya tahu dan kurang mengenal Yesus bahkan belum mengalami Yesus secara pribadi. Hal ini dapat disebabkan karena kita sendiri yang masih mempertanyakan Yesus dalam hidup kita atau bahkan menjauh dari Dia.

Apakah ada sesuatu yang membuat kalian khawatir saat ini? Kemudian peristiwa apakah dalam hidup kalian yang membuat kalian khawatir atau bahkan meragukanYesus?

Bukankah ketika kita meragukan Yesus secara tidak langsung kita telah mempertanaykan Yesus? Dan itu juga dapat berarti bahwa kita belum mengenal Yesus. Tuliskan komitmen pada sticky note ?

5) Penutup Menyanyi "Mengenal-Mu"

Bila ku buka mataku

dan lihat wajah-Mu kuterkagum

Bila kulihat hidupku

dan karya tangan-Mu kutersanjung

Karena semua yang baik dalam hidukpku

itulah karya-Mu

Kau bri kesempatan yang baru

Reef: Dan ku ingin mengenal-Mu Tuhan

lebih dalam dari semua yang kukenal

Tiada kasih yang melebihi-Mu

ku ada untuk menjadi penyembah-Mu

\section{Hasil dan Pembahsan}

Pada tahap penghubung, peserta diajak untuk berimajinasi seakan-akan mereka berada dalam peristiwa dalam nas Matius 16:13-20 melalui drama. Mahasiswa diajak untuk memposisikan diri mereka baik sebagai murid ataupun sebagai Yesus. Dalam proses inilah mahasiswa menggunakan ranah kognitifnya untuk memahami peristiwa yang terjadi. Hasil tanya jawab pada tahap ini menunjukkan bahwa mahaiswa dapat memposisikan diri mereka seperti dalam cerita Alkitab. Hal ini juga menunjukkan 
bahwa pada tahap usia mahasiswa mereka telah mencapai tahap perkembangan yang baik. Pada tahap ini peserta disebri skema tentang peristiwa dalam nas.

Pada tahap pelajaran, peserta berdiskusi dengan teman kelompok mereka alasan Yesus bertanya kepada murid-murid-Nya sebanyak 2x. Dari jawaban yang terkumpul rata-rata kelompok menjawab bahwa Yesus ingin memastikan sejauh mana mereka mengenal Yesus secara pribadi setelah mengikut Yesus sebagi murid-murid Yesus. Pada sesi ke-2 pada tahap ini setiap kelompok diminta untuk memberikan kata kunci dari nas ini. Pada tahap ini peserta memasuki tahap asimilasi yaitu proses setelah ia melihat skema maka ia mengubahnya sesuai dengan persepsi peserta. ${ }^{9}$ Hasilnya dapat terlihat dalam tabel 1.

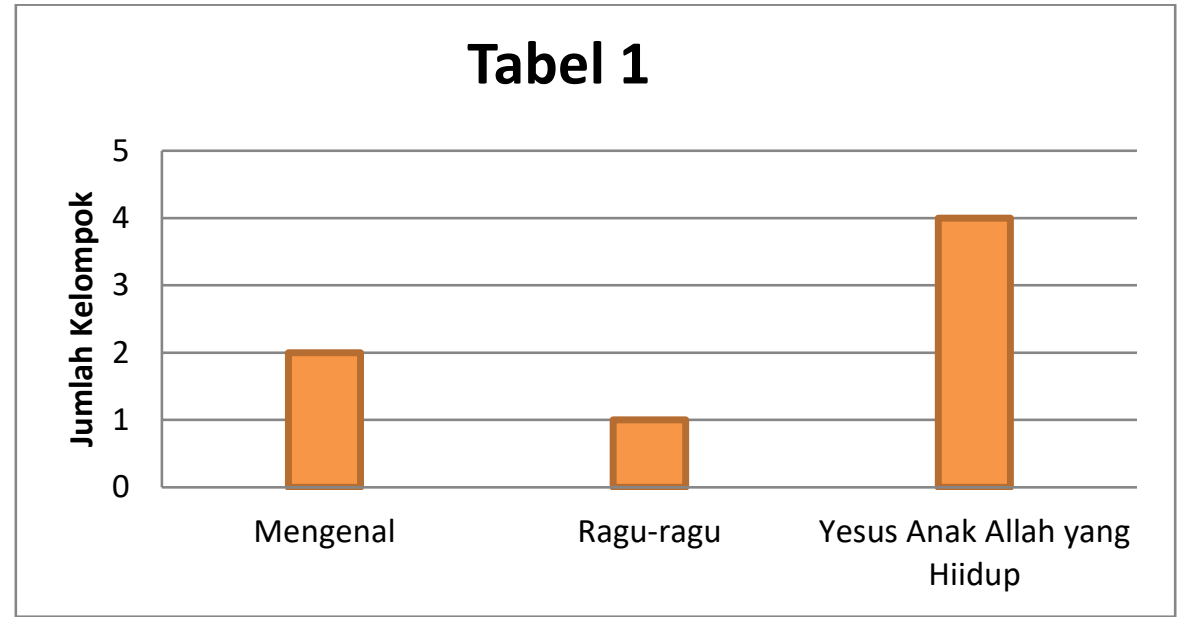

Pada tahap penerapan, peserta diberikan kesempatan untuk menceritakan (membagikan) pengalaman mereka yang berhubungan dengan teks dari nas tersebut. Ada dua orang yang membagikan pengalaman mereka. Pertama dari saudari Defli. Dia menceritakan bahwa dia tahu tentang Yesus, dia tahu Yesus itu siapa. Dia tahu dan kenal Yesus karena di sini (Kampus STFT Jaffray) dia belajar tentang Yesus. Namun, dia kurang mengalami Yesus (mengalami perjumpaan pribadi dengan Yesus). Melalui materi ini, mengingatkan saya bahwa, saya kuliah di sini menjadi hamba Tuhan, tapi saya kurang mengalami Tuhan. Hal ini mendorong saya untuk lebih dekat dengan Tuhan. Bukan hanya belajar teorinya, namun belajar untuk lebih dekat lagi dengan Tuhan. Kedua dari saudara Yulius, dia mengatakan bahwa saya tidak boleh hanya mengenal Tuhan saja, tapi saya juga harus mengalami Tuhan dalam hidup saya.

Pada tahap perubahan, peserta diajak untuk merefleksikan hubungan mereka dengan Yesus dan memberi pertanyaan aplikasi yang berkaitan dengan kekhawatiran dan kerguan yang secara tidak langsung mengarah pada pemikiran peserta yang mempertanyakan keberadaan Yesus. Dari refleksi ini peserta membuat komitmen baru sebagai perubahan agar mencapai tujuan akhir pembelajaran. Tahap ini disebut tahap akomodasi. ${ }^{10}$ Menurut Piaget proses ini disebut sebagai proses akomodasi yang mendorong individu untuk menyesuaikan dirinya yang diterimanya dari lingkungan sekitarnya. ${ }^{11}$ Keseimbangan ini terjadi anatara pola yang digunakan dengan respon terhadap lingkungan sehingga menghasilkan akomodasi yang baik dan informasi yang didapat dapat dijelaskan dengan jelas. ${ }^{12}$

\footnotetext{
${ }^{9}$ Fatimah Ibda, "Perkembangan Koognitif: Jean Piaget," Intelektualita, 3 (Juni 2015): 32. .

${ }^{10}$ Ibda.

${ }^{11}$ Fatimah Ibda, “Perkembangan Koognitif: Jean Piaget," Intelektualita, 3 (Juni 2015): 27.

${ }^{12}$ Ujang Khiyarusoleh, "Konsep Dasar Perkembangan Koognitif pada Anak Menurut Jean Piaget," Jurnal Dialektika Jurusan PGSD, 5 (Maret 2016): 1-10.
} 
Pada tahap penutup, peserta diingatkan dan dianjurkan untuk selalu meminta pertolongan Tuhan supaya peserta bukan hanya mengenal Tuhan, namun peserta juga mengalami Tuhan. Karena Tuhan yang menyatakan diri kepada setiap orang yang dikehendaki-Nya. Peserta harus selalu datang kepada Tuhan, belajar dan terus mencari Tuhan untuk mengalami Tuhan dalam hidupnya. Menurut teori perkembangan Piaget, tahap ini termasuk tahap Equilibrium, yang adalah mekanisme untuk menjelaskan bagaimana individu beralih dari satu tahap ke tahap berikutnya. ${ }^{13}$

Peserta kelas Psikologi Umum STFT Jaffray Makassar adalah mahasiswa yang berumur rata-rata 19 tahun. Pada umur ini mahasiswa telah memilki kematang cara berfikir atau perkemabngan mental sehingga mudah untuk menyerap informasi. Tahaptahap kognitif Piaget menstimulus mereka untuk berfikir secara sistematis dan mengenai semua ranah tujuan pembelajaran, baik kognitif, afektif dan psikomotor.

Pengenalan akan Yesus akan dicapai jika setiap orang percaya memilki konsep dasar yang benar tentang Yesus melalui nilai-nilai dasar Kekristenan. Ketika orang percaya memiliki konsep yang benar didukung oleh lingkungan yang baik akan mendukung orang tesebut mengenal Yesus lebih dalam. Pwngalaman pribadi dengan Yesus dapat dicapai karena Yesus sendiri yang hadir dalam hidup seseorang. ${ }^{14}$ Tetapi bukan berarti manusia lepas tangan karena manusia juga harus berusaha untuk membangun hubungan yang intim dengan Yesus. Melalui kehidupan sehari-hari pula manusia dapat merasakan pengalaman pribadi dengan Yesus. Ketika manusia telah mengalami Yesus maka pastilah orang tersebut akan memhami identitas sejatinya dan memperaktekkannya dalam kehidupan sehari-harinya.

\section{Kesimpulan}

Agama adalah identitas sejati manusia. Untuk memhami identitas ini diperlukan pengenalan yang benar akan Tuhan yang menjadi patokan utama dalam agama. Setiap orang percaya harus memiliki identitas yang jelas dihadapan Tuhan. Identitas ini bukan hnaya untuk diperlihatkan kepada orang lain tetapi untuk dipertanggungjawabkan dihadapan Tuhan. Dan Tuhan mengenal kita karena kita memilki identitas yang jelas dihadapan Tuhan. Oleh sebab itu, kita harus mengenal dan mengalami Tuhan dalam hidup kita.

Pengenalan akan Tuhan dapat dilakukan jika kita memilki konsep atau skema yang benar tentang Yesus. Konsep ini akan berkembang jika kita memiliki akomodasi hubungan yang dekat dengan Tuhan yang akan memberikan kita pengalaman pribadi dengan Tuhan. Dan cara untuk mengnal Yesus adalah membangun hubungan yang intim dengan Yesus melalu doa teduh secara rutin. Melalui doa teduh setiap pribadi merenungkan cara Yesus bekerja dalam hidupnya dan menciptakan pengalaman pribadi dengan Yesus. Ketika manusia telah mengalami Yesus maka pastilah orang tersebut akan memhami identitas sejatinya dan memperaktekkannya dalam kehidupan sehariharinya.

Saran :

1) Setiap orang percaya harus menggali dan memiliki konsep yang benar tentang Yesus. ${ }^{15}$ 2013),, 90

${ }^{13}$ Siti Aisyah Mu'min, “Teori Perkembnagan Koognitif Jean Piget,” Jurnal Ai-Ta’dib, 6 (Juni

${ }^{14}$ Daniel Ronda, Dasar Teologi yang Teguh: Panduan Teologi Sistematika Di Perguruan Tinggi (Makassar: Sekolah Tinggi Theologia Jaffray Makssar, 2013).

${ }^{15}$ Daniel Ronda, Dasar Teologi yang Teguh: Panduan Teologi Sistematika Di Perguruan Tinggi (Makassar: Sekolah Tinggi Theologia Jaffray Makassar, 2013). 
2) Pembina rohani baik pendeta harus memperdalama pembinaan doktrin yang benar dalam gereja, agar jemaat tidak mudah terpengaruh dengan doktrin yang salah. ${ }^{16}$

3) Pengenalan Allah oleh Roh Kudus sebagai ciptaan yang baru. ${ }^{17}$

4) Penyembahan kepada Allah yang benar adalah sikap hormat kepada Yesus Kristus. ${ }^{18}$

5) Penelitian ini terbatas dan diharapkan adanya penelitian yang mendalam tentang isu-isu ini karena isu ini sangat penting dalam kehidupan agama Kristen yang masih banyak belum di sadari.

\section{Kepustakan}

Anidar, Jum. "Teori Belajar Menurut Aliran Kognitif Serta Implikasinya Dalam Pembelajaran," 2014.

Ibda, Fatimah. "Perkembangan Koognitif: Jean Piaget," Intelektualita, 3 (Juni 2015): 27-38.

Kelompok Kerja Pendidikan Agama Kristen PGI. Suluh Siswa 2: Berbuah dalam Kristus (Buku Pendidkan Agama Kristen kelas 11 SMA). Jakarta: PT. BPK Gunung Mulia, 2209.

Khiyarusoleh, Ujang. "Konsep Dasar Perkembangan Koognitif pada Anak Menurut Jean Piaget," Jurnal Dialektika Jurusan PGSD, 5 (Maret 2016): 1-10.

Kushartanti, Untung Yuwono, dan Multamia, ed. Pesona Bahasa: Langkah Awal Memahami Linguistik. Jakarta: Gramedia Pustaka Umum, 2014.

Matheus, Jonathan, dan Elisabet Selfina. "Peran Pembina Remaja Bagi Perkembangan Perilaku Remaja Di Gereja Kemah Injil Indonesia Tanjung Selor Kalimantan Utara." Jurnal Jaffray 13, no. 1 (31 Januari 2015): 1-22. https://doi.org/10.25278/jj71.v13i1.3.

Mimi. Perkembangan Peserta Didik. Padang: IAIN IB Press, 2011.

Mu'min, Siti Aisyah. "Teori Perkembnagan Koognitif Jean Piget," Jurnal Ai-Ta'dib, 6 (Juni 2013): 89-99.

Mustafa, Hasan. "Perilaku Manusia Dalam Perspektif Psikologi Sosial” 7, no. 2 (2012): 143-56.

Ronda, Daniel. Dasar Teologi yang Teguh: Panduan Teologi Sistematika Di Perguruan Tinggi. Makassar: Sekolah Tinggi Theologia Jaffray Makssar, 2013. - Dasar Teologi yang Teguh: Panduan Teologi Sistematika Di Perguruan Tinggi. Makassar: Sekolah Tinggi Theologia Jaffray Makassar, 2013.

Sujiono, Yuliani Nurani. "Hakikat Pengembangan Kognitif," t.t., 1-35.

Sutarto. "Teori Koognitif dan Implikasinya Dalam Pembelajaran,” Jurnal Konseling Islam, 1 (2017): 1-26.

\footnotetext{
${ }^{16}$ Jonathan Matheus dan Elisabet Selfina, "Peran Pembina Remaja Bagi Perkembangan Perilaku Remaja Di Gereja Kemah Injil Indonesia Tanjung Selor Kalimantan Utara,” Jurnal Jaffray 13, no. 1 (31 Januari 2015): 1-22, https://doi.org/10.25278/jj71.v13i1.3.

${ }^{17}$ Hengki Wijaya, "Pengenaan Manusia Baru Di Dalam Kristus: Natur, Proses, Dan Fakta Serta Implikasi Teologis Dan Praktisnya,” Jurnal Jaffray 14, no. 1 (22 Maret 2016): 109, https://doi.org/10.25278/jj71.v14i1.194.

${ }^{18}$ Hengki Wijaya, "Ulasan Buku: Whatever Happened To Worship A Call To True Worship," Jurnal Jaffray 15, no. 1 (19 Maret 2017): 148, https://doi.org/10.25278/jj71.v15i1.241.
} 
Suyono, Haryanto. Teori Belajar dan Pembelajaran. Bnadung: Remaja Rosdakarya, 2010.

Wijaya, Hengki. "Pengenaan Manusia Baru Di Dalam Kristus: Natur, Proses, Dan Fakta Serta Implikasi Teologis Dan Praktisnya." Jurnal Jaffray 14, no. 1 (22 Maret 2016): 109. https://doi.org/10.25278/jj71.v14i1.194.

- "Ulasan Buku: Whatever Happened To Worship A Call To True Worship." Jurnal Jaffray 15, no. 1 (19 Maret 2017): 148.

https://doi.org/10.25278/jj71.v15i1.241.

Wijaya, Hengki, dan Arismunandar Arismunandar. "Pengembangan Model Pembelajaran Kooperatif Tipe STAD Berbasis Media Sosial.” Jurnal Jaffray 16, no. 2 (6 Oktober 2018): 175-96. https://doi.org/10.25278/jj71.v16i2.302.

Wijaya, Hengki, dan Helaluddin Helaluddin. Analisis Data Kualitatif Sebuah Tinjauan Teori \& Praktik. Makassar: Sekolah Tinggi Theologia Jaffray Makassar, 2019. 